\title{
Paracellular epithelial sodium transport maximizes energy efficiency in the kidney
}

\author{
Lei Pei, ${ }^{1}$ Glenn Solis, ${ }^{2}$ Mien T.X. Nguyen, ${ }^{3}$ Nikhil Kamat, ${ }^{3}$ Lynn Magenheimer, ${ }^{1}$ Min Zhuo, ${ }^{1}$ Jiahua Li, ${ }^{1}$ Joshua Curry, \\ Alicia A. McDonough, ${ }^{3}$ Timothy A. Fields, ${ }^{1}$ William J. Welch, ${ }^{2}$ and Alan S.L. Yu ${ }^{1}$ \\ 1Kidney Institute, University of Kansas Medical Center, Kansas City, Kansas, USA. ²Division of Nephrology and Hypertension, Georgetown University Medical Center, Washington, DC, USA. \\ ${ }^{3}$ Department of Cell and Neurobiology, University of Southern California Keck School of Medicine, Los Angeles, California, USA.
}

\begin{abstract}
Efficient oxygen utilization in the kidney may be supported by paracellular epithelial transport, a form of passive diffusion that is driven by preexisting transepithelial electrochemical gradients. Claudins are tight-junction transmembrane proteins that act as paracellular ion channels in epithelial cells. In the proximal tubule (PT) of the kidney, claudin-2 mediates paracellular sodium reabsorption. Here, we used murine models to investigate the role of claudin- 2 in maintaining energy efficiency in the kidney. We found that claudin-2-null mice conserve sodium to the same extent as WT mice, even during profound dietary sodium depletion, as a result of the upregulation of transcellular $\mathrm{Na}-\mathrm{K}-2 \mathrm{Cl}$ transport activity in the thick ascending limb of Henle. We hypothesized that shifting sodium transport to transcellular pathways would lead to increased whole-kidney oxygen consumption. Indeed, compared with control animals, oxygen consumption in the kidneys of claudin-2-null mice was markedly increased, resulting in medullary hypoxia. Furthermore, tubular injury in kidneys subjected to bilateral renal ischemiareperfusion injury was more severe in the absence of claudin-2. Our results indicate that paracellular transport in the PT is required for efficient utilization of oxygen in the service of sodium transport. We speculate that paracellular permeability may have evolved as a general strategy in epithelial tissues to maximize energy efficiency.
\end{abstract}

\section{Introduction}

Epithelia are sheets of cells that separate body compartments of different compositions and function as physical and chemical barriers. For almost a century, it was believed that epithelial cells were attached to each other by an impermeable seal that was referred to as the "terminal bar." The introduction of electron microscopy in the 1950s led to the description of the intercellular junctional complex and tight junctions $(1,2)$. Shortly thereafter, it became apparent, particularly in leaky epithelia, that so-called "tight" junctions actually constitute a paracellular pathway that allows passive permeability to small ions and macromolecules (3-7). The mainstay of transepithelial transport is clearly transcellular transport, which is mediated by transmembrane transport proteins at the apical and basolateral plasma membrane. Transmembrane transport proteins are notable for their heterogeneity (being encoded by $\sim 1,000$ distinct genes) $(8,9)$, substrate specificity, and regulation over a remarkably dynamic range of activities by means of gene transcription, translation, protein stability, and trafficking. Given the vast capabilities and flexibility of transcellular transport, a fundamental and highly significant question in biology is: Why did epithelia evolve the capability for paracellular transport?

The kidney has certain features that make it a particularly good organ system in which to answer this fundamental question (10). Although the kidneys receive $25 \%$ of the cardiac out-

Conflict of interest: The authors have declared that no conflict of interest exists. Submitted: July 27, 2015; Accepted: April 5, 2016.

Reference information: J Clin Invest. 2016;126(7):2509-2518. doi:10.1172/JCI83942. put, the oxygen tension in kidney tissue is low, ranging from $10 \mathrm{mmHg}$ in the inner medulla to $40 \mathrm{mmHg}$ in the cortex (11). Moreover, unlike all other organs, the kidney cannot enhance its oxygenation simply by increasing renal blood flow. Increasing renal blood flow does indeed increase oxygen delivery; however, it also increases the glomerular filtration rate (GFR) and hence tubule salt transport in parallel through a glomerulotubular balance, and so it simultaneously increases energy demand and hence oxygen consumption. Thus, under normal conditions, the kidney medulla cannot help but live persistently "on the edge of hypoxia." In this rather tenuous situation, the efficiency with which oxygen is utilized by the kidney becomes a critical determinant of kidney oxygen tension. Renal oxygen consumption is determined primarily by the energy required to drive tubular sodium reabsorption (12), which should be theoretically predictable. Transcellular transport of $\mathrm{Na}^{+}$is dependent on the potential energy generated by Na-K-ATPase, which uses 1 molecule of ATP to directly drive the transport of $3 \mathrm{Na}^{+}$ ions. Ninety-five percent of ATP in the kidney is generated by aerobic respiration (13), which produces 6 molecules of ATP for each molecule of $\mathrm{O}_{2}$ consumed. Thus, the ratio of suprabasal renal oxygen consumption $\left(\mathrm{QO}_{2}\right)$ to $\mathrm{Na}^{+}$reabsorption $\left(\mathrm{T}_{\mathrm{Na}}\right)$ is predicted to be $1: 18(\mathrm{~mol} / \mathrm{mol})$. Alternative pathways for basolateral $\mathrm{Na}^{+}$efflux that are indirectly driven by Na-K-ATPase, such as the electrogenic $\mathrm{Na}^{+}$-bicarbonate cotransporter in the proximal tubule $(\mathrm{PT})$, can increase $\mathrm{T}_{\mathrm{Na}}$ modestly. However, experimentally measured values of $\mathrm{QO}_{2} / \mathrm{T}_{\mathrm{Na}}$ are in the range of 1:25 to $1: 29$ (14-17), indicating that the kidney uses oxygen much more efficiently than was expected. 
A

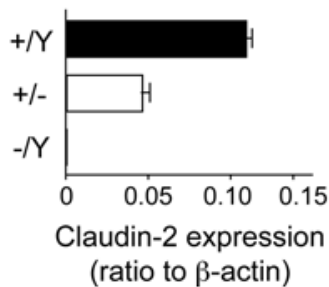

C
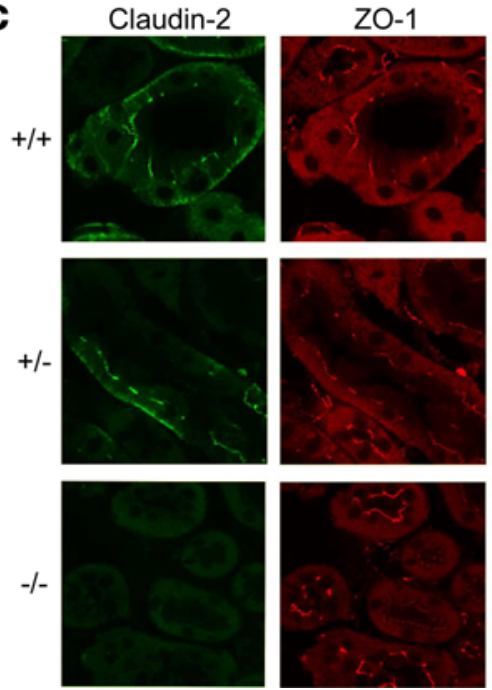
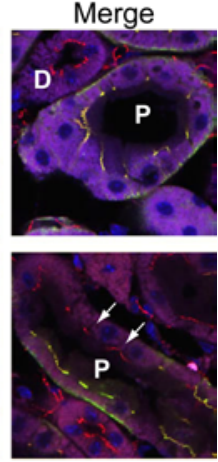

B

Claudin-2

$\beta$-Actin
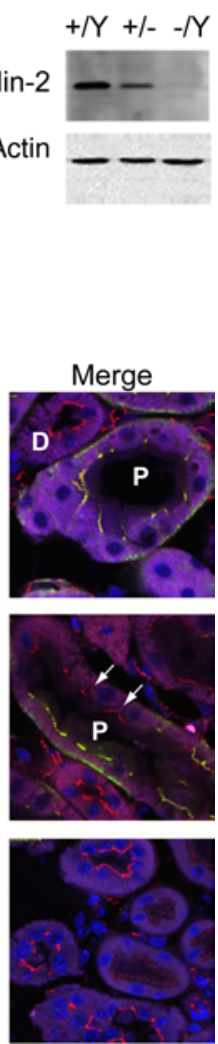

One explanation that has been proposed for this enhanced efficiency of oxygen usage is that the PT leverages the excess free energy in solute gradients established by active transcellular transport to drive additional, paracellular reabsorption of $\mathrm{Na}^{+}, \mathrm{Cl}^{-}$, and other solutes in a purely passive manner (i.e., not requiring additional energy expenditure) $(18,19)$. Transcellular reabsorption of $\mathrm{Na}^{+}$in the early PT is coupled largely to either $\mathrm{HCO}_{3}$ or organic solutes (with a small amount of $\mathrm{Cl}^{-}$reabsorbed by $\mathrm{Cl}^{-}$-base exchange). This, together with near-isosmotic water reabsorption, produces a luminal fluid that, by the time it reaches the late PT, has relatively high concentrations of $\mathrm{Cl}^{-}$and low concentrations of $\mathrm{HCO}_{3}$. The late PT is more permeable to $\mathrm{Cl}^{-}$than is $\mathrm{HCO}_{3}\left(\mathrm{P}_{\mathrm{Cl}} /\right.$ $\mathrm{P}_{\mathrm{HCO} 3}$ ranging from 2 to 18 ; refs. 20, 21). This permits a net passive reabsorption of $\mathrm{Cl}^{-}$, which is thought to occur via paracellular diffusion, and generates a lumen-positive electrical potential (22). This voltage, in turn, provides the driving force for passive reabsorption of $\mathrm{Na}^{+}$, again presumably via the paracellular pathway. It has been estimated that $32 \%$ to $64 \%$ of superficial PT NaCl reabsorption is passive and paracellular (reviewed in ref. 23).

Figure 2. Effect of claudin-2 KO on renal Na+handling. (A) Effect of dietary $\mathrm{Na}^{+}$depletion. Urine $\mathrm{Na}$ excretion rate, expressed as the ratio of $\mathrm{Na}$ to creatinine ( $\mathrm{Cr}$ ) concentration (mean $\pm \mathrm{SEM}, n=4-5$ per group), is shown in mice on a normal ( $0.3 \%$ ) Na diet (day 1 to day 5 ), followed by a $\mathrm{Na}^{+}$-deficient $(0.01 \%)$ diet (day 6 to day 9). (B) Furosemide (Fur) challenge test. Mice were administered vehicle (Veh) i.p. on the first day and furosemide $25 \mathrm{mg} / \mathrm{kg}$ on the second day. Urine $\mathrm{Na}^{+}$excretion after furosemide was greater in KO mice than in WT mice. ${ }^{*} P<0.05$, by paired Student's $t$ test ( $n=7-9$ per group).

Figure 1. Characterization of claudin-2-KO mice. (A) Quantification of whole-kidney mRNA levels of claudin-2 relative to $\beta$-actin in claudin-2 hemizygous KO $(-/ Y)$, heterozygous $(+/-)$, and WT $(+/ Y)$ mice $(n=6$ per group). (B) Western blot of whole-kidney lysates probed with mouse anticlaudin-2 antibody showing a band at the expected size for claudin-2. Lower panel shows an immunoblot for $\beta$-actin as a loading control. (C) Immunolocalization of claudin-2. Frozen sections of mouse kidney were double stained with claudin-2 antibody (green) and antibody against ZO-1 (red), a tight-junction marker. Note the localization of claudin-2 in WT kidney to the tight junctions of the PTs $(P)$ but not to the distal tubules (D), as well as the faint basolateral staining. In heterozygous mice, PT staining was heterogeneous, with claudin-2 absent from some cells (arrows) but present in others as a result of lyonization.

The tight junction is composed of a complex of multiple proteins, of which the claudins are now believed to form the paracellular pores or channels (see refs. 24-26 for several recent reviews). Claudins are encoded by a family of 27 genes in mammals (27). They are transmembrane proteins with 4 transmembrane segments and 2 extracellular domains (28). Claudin-2 is highly expressed in the PT, particularly in the late segments (29, 30 ) and has been shown in vitro to function as a high-conductance paracellular $\mathrm{Na}^{+}$channel (31-33). To determine its in vivo function, Muto et al. generated claudin-2-KO mice. In isolated, perfused PT S2 segments from these mice, there was a 2.5 -fold increase in transepithelial resistance (TER), a decrease in the $\mathrm{Na}^{+} / \mathrm{Cl}^{-}$permeability ratio $\left(\mathrm{P}_{\mathrm{Na}} / \mathrm{P}_{\mathrm{Cl}}\right)$, and a $37 \%$ decrease in net $\mathrm{Na}^{+}$reabsorption, demonstrating that claudin-2 plays a major role in PT paracellular $\mathrm{Na}^{+}$transport (34). Schnermann et al. subsequently confirmed that these mice have a $23 \%$ reduction in proximal fluid reabsorption (35). Although it was predicted that these mice would exhibit urinary $\mathrm{NaCl}$ wasting, this was not observed in metabolic balance studies in mice on a normal diet, raising the question of what role, if any, claudin-2 plays in normal physiology.

It is currently unknown to what extent paracellular transport in the PT affects renal $\mathrm{O}_{2}$ utilization in vivo or whether this is physiologically important. The ability to ablate PT paracellular $\mathrm{Na}^{+}$transport by gene targeting of claudin- 2 in mice afforded us a unique opportunity to test this directly. Here, we show that mice null for claudin-2 are able to compensate completely for loss of paracellular $\mathrm{Na}^{+}$transport in the PT by upregulating transcellular $\mathrm{Na}^{+}$reabsorption in the thick ascending limb, but at the expense of decreased efficiency of $\mathrm{O}_{2}$ utilization, medullary hypoxia, and increased susceptibility to ischemic tubular injury. We believe our results provide an explanation for why paracellular permeability evolved in the kidney.
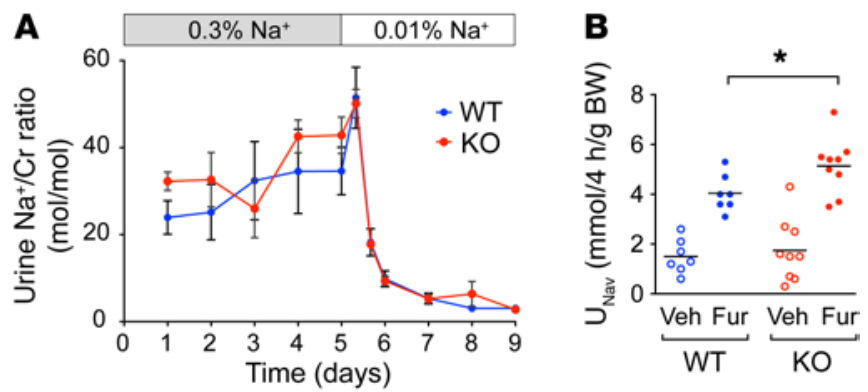
Table 1. Renal hemodynamics and function in anesthetized mice

$\begin{array}{lccc} & \text { WT }(\boldsymbol{n}=\mathbf{8}) & \text { KO }(\boldsymbol{n}=\mathbf{9}) & \boldsymbol{P} \text { value } \\ \mathrm{CFR}(\mu \mathrm{l} / \mathrm{min} / \mathrm{g} \mathrm{KW} & 846 \pm 40 & 911 \pm 38 & 0.26 \\ \mathrm{RBF}(\mathrm{ml} / \mathrm{min} / \mathrm{g} \mathrm{KW} & 7.69 \pm 0.35 & 7.72 \pm 0.24 & 0.96 \\ \mathrm{MAP}(\mathrm{mmHg}) & 101.8 \pm 3.3 & 105.1 \pm 2.6 & 0.45 \\ \mathrm{~T}_{\mathrm{Na}}(\mu \mathrm{mol} / \mathrm{min} / \mathrm{g} \mathrm{KW}) & 126.9 \pm 6.0 & 138.2 \pm 6.3 & 0.22 \\ \mathrm{QO}_{2}(\mu \mathrm{mol} / \mathrm{min} / \mathrm{g} \mathrm{KW}) & 8.06 \pm 0.74 & 14.50 \pm 1.55 & 0.003 \\ \mathrm{~T}_{\mathrm{Na}} / \mathrm{QO}_{2}(\mathrm{~mol} / \mathrm{mol} \mathrm{KW}) & 16.36 \pm 1.31 & 10.34 \pm 1.33 & 0.007\end{array}$

\section{Results}

Claudin-2-null mice retain the ability to maximally conserve $\mathrm{Na}^{+}$. Previous studies have demonstrated that claudin-2-null mice have marked impairment of PT reabsorption of $\mathrm{Na}^{+}, \mathrm{Cl}^{-}$, and $\mathrm{H}_{2} \mathrm{O}$, yet they have no defect in renal $\mathrm{Na}^{+}$conservation under normal conditions. We initially set out to test the hypothesis that claudin- 2 contributes a reserve capacity to the normal ability of the tubule to reabsorb $\mathrm{Na}^{+}$. We predicted that claudin- 2 and PT paracellular $\mathrm{Na}^{+}$transport would be superfluous under normal conditions because of compensation, presumably by distal, transcellular $\mathrm{Na}^{+}$transport. However, under extreme conditions of salt or extracellular volume depletion, claudin- 2 would be required to maximally conserve urinary $\mathrm{Na}^{+}$.

To test this hypothesis, we purchased claudin-2-constitutive KO mice from the Mutant Mouse Regional Resource Centers and bred them onto a pure C57BL/6 background. Claudin-2-null mice were born at the expected Mendelian genotype ratios. There was no overt phenotype, and they bred normally and survived normally. Because the claudin-2 gene is on the $\mathrm{X}$ chromosome, we used male hemizygous mice $(-/ \mathrm{Y})$ as the KOs and compared them with their male WT littermates (+/Y) for matched controls (WT). Quantitative real-time RT-PCR (qRT-PCR) and Western blotting confirmed an absent expression of claudin- 2 in hemizygous $\mathrm{KO}$ $(-/ Y)$ mice compared with that seen in $\mathrm{WT}(+/ \mathrm{Y})$ mice (Figure 1, A and B). There was an intermediate level of expression of claudin-2 in heterozygous female (+/-) mice. Immunofluorescence confirmed that claudin-2 was expressed and localized in tight junctions in WT mouse kidney PTs in a continuous distribution, but was absent from the KO mouse kidneys. Heterozygous kidneys showed a discontinuous distribution of claudin-2 in only some of the PT cells, presumably due to lyonization (Figure 1C).

The general characterization of claudin-2-KO mice was similar to that in previous reports (34). The serum concentrations of potassium and aldosterone were no different between KO and WT mice, whereas kidney renin levels were slightly but significantly reduced in the KO mice (Supplemental Figures 3 and 4; supplemental material available online with this article; doi:10.1172/ JCI83942DS1). Infusing the mice with hypertonic saline (2\% $\mathrm{NaCl})$ resulted in a higher urine $\mathrm{Na}^{+}$excretion rate in claudin-2KO mice compared with that detected in WT mice (Supplemental Figure 5), as was previously described by Muto et al. (34).

To investigate whether other paracellular transport pathways were upregulated to compensate for the lack of claudin-2, we performed qRT-PCR for other claudins expressed in the PT (claudin10a and claudin-17), thick ascending limb (claudin-10b, -16, -19), or distal tubule (claudin-4 and claudin-8). We found no difference in the expression or localization of any of these claudins between $\mathrm{KO}$ and WT mice (Supplemental Figures 6 and 7).

Next, age-matched adult (8-week-old) claudin-2 WT and -KO mice were placed in metabolic cages and were fed a control diet with normal sodium content $\left(0.3 \% \mathrm{Na}^{+}, 0.8 \% \mathrm{~K}\right)$ for 5 days. Urine collected daily showed no significant difference in the urine $\mathrm{Na}^{+} / \mathrm{cre}$ atinine concentration ratio between the WT and KO mice (Figure 2A). After the 5-day acclimatization period, the mice were switched to a matched, $\mathrm{Na}^{+}$-deficient diet $\left(<0.01 \% \mathrm{Na}^{+}\right)$, and urine $\mathrm{Na}^{+}$was monitored every 8 hours for the first 24 hours and daily thereafter. If the $\mathrm{KO}$ mice had a defect in their ability to maximally conserve $\mathrm{Na}^{+}$, this should have manifested as a transiently higher $\mathrm{Na}^{+}$excretion rate compared with that of WT mice, one that would return to steady-state levels within a few days. To our surprise, we found no difference whatsoever (Figure 2A). Like WT mice, claudin-2-KO mice were able to fully suppress urinary $\mathrm{Na}^{+}$excretion by more than $90 \%$. There was also no difference in blood pressure (BP), measured by the tail-cuff method using volume pressure recording, or in BW (data not shown). This suggests that the salt wasting from the PT was completely compensated by increased $\mathrm{Na}^{+}$reabsorption elsewhere in the tubule.

Claudin-2-null mice exhibit lower efficiency of oxygen utilization and renal medullary hypoxia. Despite the substantial defect in $\mathrm{PT}$ paracellular $\mathrm{Na}^{+}$transport, it is remarkable that claudin-2-KO mice are able to maximally conserve $\mathrm{Na}^{+}$, even on a diet of severe $\mathrm{Na}^{+}$restriction. We speculated that this might be due to a compensatory increase in the activity of transcellular $\mathrm{Na}^{+}$transporters further downstream along the nephron. This raises the obvious question of what physiological role paracellular transport plays. If transcellular transport can completely compensate for paracellular transport, even under the most extreme conditions, does this come with any cost to the organism, or is paracellular transport simply a vestigial process? We hypothesized that paracellular transport in the PT exists to exploit transtubular electrochemical gradients to drive passive transport of $\mathrm{NaCl}$ and hence to maximize the efficiency with which this tubule segment utilizes $\mathrm{O}_{2}$ to reabsorb $\mathrm{NaCl}$. Therefore, if the burden of $\mathrm{NaCl}$ reabsorption in claudin-2-KO mice is shifted distally, our hypothesis predicts that these mice will have increased renal $\mathrm{O}_{2}$ consumption.
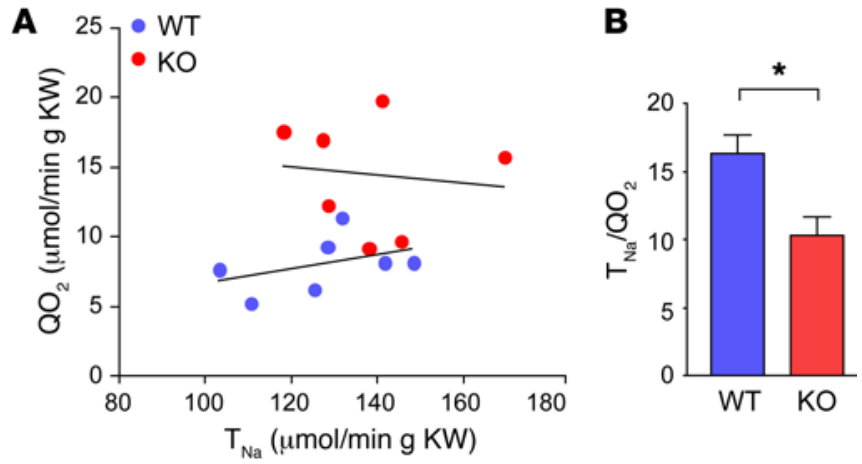

Figure 3. Role of claudin-2 in renal $\mathbf{O}_{2}$ utilization. (A) Relationship between $\mathrm{T}_{\mathrm{Na}}$ and $\mathrm{QO}_{2}$ in individual claudin-2 WT and $\mathrm{KO}$ mice, expressed per gram of $\mathrm{KW}$. (B) Efficiency of $\mathrm{O}_{2}$ utilization for renal $\mathrm{Na}^{+}$transport, $\mathrm{T}_{\mathrm{Na}} / \mathrm{QO}_{2}$, calculated from the data in $\mathbf{A}$ ( $n=7$ per group). ${ }^{*} P<0.01$, by Student's $t$ test. 
A

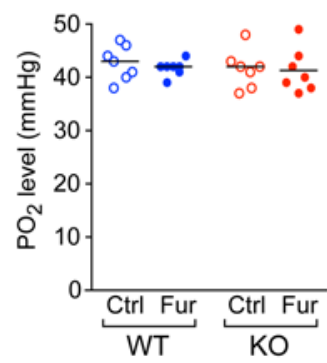

B

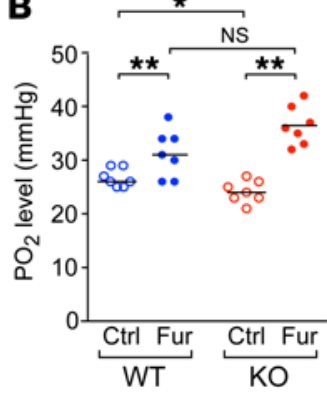

C

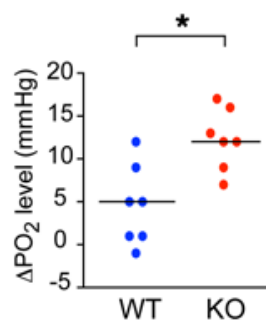

Figure 4. Effect of claudin-2 $\mathrm{KO}$ on intrarenal $\mathrm{PO}_{2}$, as measured with $\mathrm{O}_{2}$-sensing microelectrodes. ( $\mathrm{A}$ and $\mathrm{B}$ ) $\mathrm{PO}_{2}$ in kidney cortex (A) and outer medulla (B) at baseline (Ctrl) and after treatment with furosemide. ${ }^{*} P=0.01$ and ${ }^{* *} P<0.001$, by 2-way ANOVA with simple-effects testing. (C) Change in $\left.\mathrm{PO}_{2}(\triangle \mathrm{PO})_{2}\right)$ in the outer medulla induced by furosemide $(n=7$ per group). ${ }^{*} P<0.005$, by Student's $t$ test.
To test this hypothesis, we determined the ratio between whole-kidney $\mathrm{Na}^{+}$reabsorption $\left(\mathrm{T}_{\mathrm{Na}}\right)$ and oxygen consumption $\left(\mathrm{QO}_{2}\right)$ in anesthetized WT and $\mathrm{KO}$ mice. $\mathrm{T}_{\mathrm{Na}}$ was calculated from the difference between the filtered load of sodium (GFR, determined from insulin clearance, multiplied by $\mathrm{P}_{\mathrm{Na}}$ ) and renal $\mathrm{Na}^{+}$ excretion $\left(\mathrm{U}_{\mathrm{Na}} \mathrm{V}\right) . \mathrm{QO}_{2}$ was determined from the renal blood flow (RBF) (assessed by para-aminohippurate [PAH] clearance), factored by the arterial-venous $\mathrm{O}_{2}$ difference. GFR, $\mathrm{RBF}$, and mean arterial pressure (MAP) were not different between the groups. $\mathrm{T}_{\mathrm{Na}}$ was also similar between WT and $\mathrm{KO}$ mice, whereas $\mathrm{QO}_{2}$ was $80 \%$ higher in $\mathrm{KO}$ mice $(P<0.005))$, resulting in a nearly $40 \%$ lower $\mathrm{T}_{\mathrm{Na}} / \mathrm{QO}_{2}$ ratio $(P<0.01)$ in $\mathrm{KO}$ mice (Table 1 and Figure 3 ).

To investigate the effect of this increase in oxygen consumption on intrarenal oxygenation, we measured $\mathrm{PO}_{2}$ in the outer medulla and cortex with an $\mathrm{O}_{2}$-sensing microelectrode. In the outer medulla, claudin-2-KO kidney exhibited a lower $\mathrm{PO}_{2}$ than did WT kidney $(P=0.01)$, whereas in the cortex, claudin-2-KO and WT kidneys had similar $\mathrm{PO}_{2}$ levels (Figure 4). Treatment with furosemide increased $\mathrm{PO}_{2}$ levels in the outer medulla of mice of both genotypes. However, this increase was 2.7-fold greater in $\mathrm{KO}$ mice than in WT mice $(P<0.005)$ (Figure $4 \mathrm{C})$, so that the $\mathrm{PO}_{2}$ level after furosemide was no longer significantly different between the KO and WT mice $(P=0.068)$ (Figure $4 \mathrm{~B})$. These findings strongly suggest that there may be increased $\mathrm{Na}-\mathrm{K}-2 \mathrm{Cl}$ cotransporter (NKCC2) activity in the thick ascending limb of Henle (TALH).

Compensatory increase in $\mathrm{Na}^{+}$reabsorption in the thick ascending limb of claudin-2-KO mice. To investigate whether there was upregulation in the expression of transcellular $\mathrm{Na}^{+}$transporters, we immunoblotted whole-kidney lysates to detect major renal tubule transcellular $\mathrm{Na}^{+}$transport proteins (Supplemental Figure 8). The protein abundance of total and activated (phosphorylated or cleaved, as appropriate) forms of Na-K-ATPase, Na-Cl cotransporter (NCC), NKCC2, and epithelial $\mathrm{Na}^{+}$channel (ENaC) $\alpha, \beta$, and $\gamma$ subunits was no different between WT and KO mice. Total $\mathrm{Na}^{+} / \mathrm{H}^{+}$exchanger 3 (NHE3) showed a $23 \%$ reduction and phosphorylated NHE3 showed a $27 \%$ reduction in claudin-2-KO kidneys (Supplemental Figure 8), but no difference was detectable by immunofluorescence staining (Supplemental Figure 9).

To confirm whether there was a functional increase in the activity of NKCC2 in claudin-2-KO mice and to test for increased activity of transcellular $\mathrm{Na}^{+}$transporters in other nephron segments, we performed a diuretic challenge experiment. Mice were given single i.p. injections of vehicle or diuretic on consecutive days, and urine was collected over a 4-hour period after each injection to determine the $\mathrm{Na}^{+}$excretion rate (Supplemental Figure 10).
This was repeated weekly in the same set of mice with 3 different diuretics: furosemide, an NKCC2 blocker, hydrochlorothiazide (HCTZ), an NCC blocker, and benzamil, an ENaC blocker. WT mice responded to all 3 diuretics with a brisk natriuresis compared with the response observed with vehicle injection. KO mice had $40 \%$ greater natriuresis in response to furosemide than did WT mice (Figure 2B), consistent with increased activity of the Na-K$2 \mathrm{Cl}$ cotransporter NKCC2 in the TALH as the primary mechanism for compensation. The diuretic response to HCTZ and benzamil was also modestly increased, but the difference was not statistically significant (Supplemental Figure 11).

Claudin-2-null mice are more susceptible to ischemic injury. Since claudin-2-null mice exhibit lower efficiency of oxygen utilization and renal medullary hypoxia, we hypothesized that claudin-2-null kidneys would be more susceptible to kidney injury from oxygen and ATP depletion. To test this hypothesis, we subjected WT and KO mice to bilateral renal ischemia-reperfusion injury (IRI). As shown in Figure 5A and Supplemental Figure 12, the blood urea nitrogen (BUN) level increased in both WT and KO mice 24 hours and 48 hours after reperfusion. However, the extent of elevation at both time points was much higher in KO mice than in WT mice $(P<0.005)$. We hypothesized that the increased susceptibility of $\mathrm{KO}$ mice to ischemic injury was due to increased activity and hence oxygen consumption by NKCC2, so we tested whether pretreatment with furosemide 2 hours before ischemia could prevent injury. Consistent with this hypothesis, the BUN elevation in KO mice 24 and 48 hours after reperfusion was ameliorated by furosemide $(P<0.01)$, whereas the diuretic had no effect in WT mice. The plasma creatinine concentration was also significantly higher in $\mathrm{KO}$ mice compared with that in WT mice at 48 hours following reperfusion $(1.45 \mathrm{mg} / \mathrm{dl}$ vs. $0.33 \mathrm{mg} / \mathrm{dl}, P<0.005)$ and was reduced by furosemide pretreatment in KO mice $(P<0.05)$ but not in WT mice (Figure 5B). Kidney injury molecule 1 (KIM-1) is a commonly used early marker of kidney injury and correlates positively with the degree of renal damage in both acute and chronic injuries $(36,37)$. The mRNA level of Kim1 showed trends that were identical to those for BUN and creatinine (Figure $5 \mathrm{C}$ ), and $\mathrm{KIM}-1$ protein expression by IHC showed consistent findings (Supplemental Figure 13).

Morphological studies at 48 hours showed evidence of tubular injury (e.g., tubular necrosis, sloughed cells, mitotic figures, and luminal casts) that was most readily identified within the S3 segment of the PT. In WT mice, only a portion of the renal tubules $(\sim 50 \%)$ in the outer medulla showed morphological features of ischemic injury such as loss of the brush border, flattening of the epithelium, tubular necrosis, and luminal casts, while the renal 
A

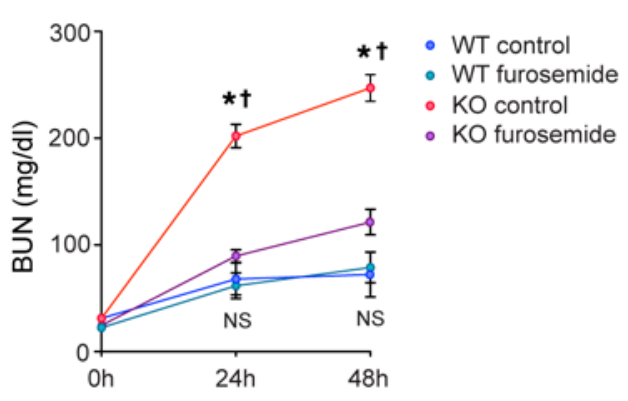

B

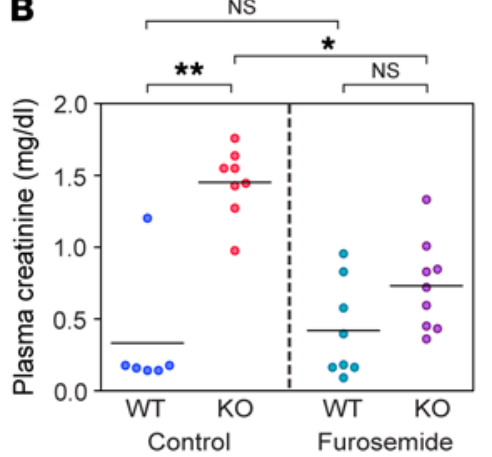

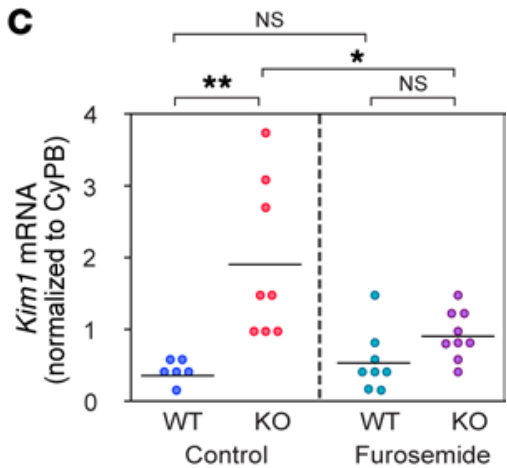

Figure 5. Effect of claudin-2 KO on susceptibility to acute renal ischemia. (A) BUN levels at 0,24 , and 48 hours following bilateral renal IRI in claudin-2$\mathrm{KO}$ mice and their WT littermates, with furosemide or without (control) pretreatment. ${ }^{*} P<0.005$ for KO control versus WT control; ${ }^{\dagger} P<0.01$ for KO control versus KO furosemide; NS, $P$ value was not significant for WT control versus WT furosemide ( $n=6-9$ per group); 3-way ANOVA with simple-effects testing. (B and C) Plasma creatinine and kidney Kim1 mRNA levels normalized to cyclophilin B (CyPB) 48 hours after IRI. ${ }^{*} P<0.05$ and ${ }^{* *} P<0.005$, by 2 -way ANOVA with simple-effects testing.

cortex was almost completely intact. However, in KO mice, almost all the renal tubules $(\sim 95 \%)$ in the outer medulla exhibited ischemic injury, and tubule injury, especially within proximal tubules, was also observed in parts of the renal cortex (Figure 6). We graded the severity of the renal tubular injury by estimating the proportion of the entire kidney area that was involved. The KO kidneys had a larger area of injury compared with WT kidneys $(P<0.005)$. Finally, pretreatment with furosemide had no significant effect on the severity of injury in WT mice, but significantly ameliorated the injury score in KO mice ( $P=0.018$, Figure 6 and Supplemental Figure 14). These findings suggest that claudin-2-null mice are more susceptible to acute ischemic renal injury and that this is because of upregulated NKCC2 activity in the TALH and hence increased outer medullary oxygen consumption.

\section{Discussion}

Our results show that claudin-2-KO mice compensate for loss of paracellular $\mathrm{Na}^{+}$reabsorption in the $\mathrm{PT}$ by upregulating thick ascending limb transcellular transport, at the expense of increased oxygen consumption. The mechanism of upregulated TALH Na+ reabsorption remains to be determined. Because there was no change in expression levels of the major paracellular and transcellular transport proteins in claudin-2-KO mice, but there was increased natriuresis in response to furosemide, we attribute the compensatory increase in $\mathrm{Na}^{+}$reabsorption to a change in the functional activity of NKCC2. Moreover, we found that the difference of $\mathrm{P}_{\mathrm{O} 2}$ before and after furosemide treatment $\left(\Delta \mathrm{P}_{\mathrm{O} 2}\right)$, which represents the amount of $\mathrm{O}_{2}$ consumed by NKCC2 in the thick ascending limb, was 2.7-fold greater in claudin-2-KO mice (Figure 4C). This provides additional evidence that medullary NKCC2 activity is increased. We speculate that this is due to the increase in $\mathrm{Na}^{+}$load delivered to the loop of Henle, particularly to the medullary TALH. Studies done more than 40 years ago, either by free-flow micropuncture with saline expansion (38) or by tubule microperfusion at varying flow rates (39), clearly showed that the loop of Henle increases $\mathrm{Na}^{+}$reabsorption in response to the delivered load. More recently, the Cowley and Garvin laboratories have shown that an increase in flow to the TALH increases
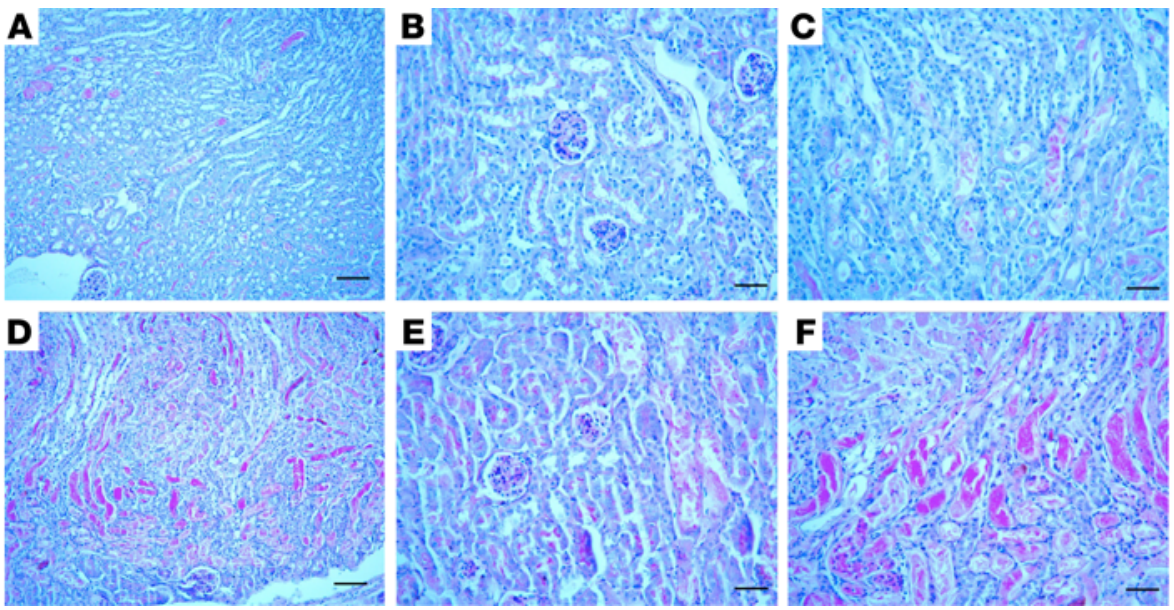

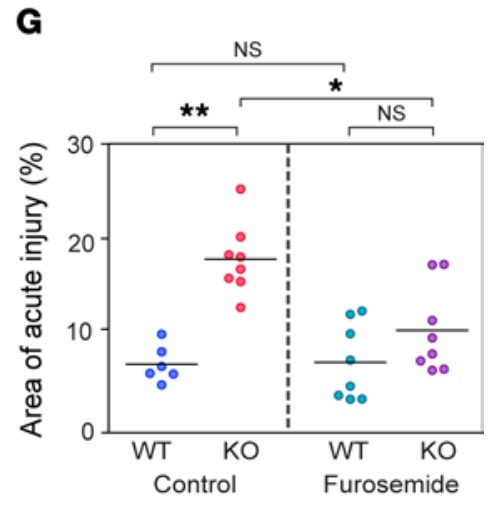

Figure 6. Histological analysis of acute kidney injury. Representative images of PAS-stained WT (A-C) and KO (D-F) kidneys 48 hours after IRI. Panels A and $\mathbf{D}$ show low-power views (scale bars: $100 \mu \mathrm{m}$ ); panels $\mathbf{B}$ and $\mathbf{E}$ show high-power views of the cortex; and panels $\mathbf{C}$ and $\mathbf{F}$ show high-power views of the outer medulla. Scale bars: $50 \mu \mathrm{m}$. (G) Histological scoring of acute injury, expressed as the percentage of kidney area involved. ${ }^{*} P<0.01$ and ${ }^{* *} P<0.001$, by Student's $t$ test ( $n=6-8$ per group). 
the generation of superoxide and secondarily reduces the bioavailability of NO, both of which can stimulate NKCC2 activity (40-44). An alternative mechanism can also be postulated, whereby high tubular flow rates could increase TALH Na+ reabsorption, even in the absence of any change in the surface density and activity of NKCC2. Burg proposed a model in which, if the capacity for $\mathrm{Na}^{+}$reabsorption in the TALH is sufficiently large that it is not rate limiting, the luminal $\mathrm{Na}^{+}$concentration will be lowered until it reaches a limiting concentration or "static head" (45). In this scenario, increases in the tubular flow rate would simply shift the point at which the static head is attained distally along the TALH, so that the rate of $\mathrm{Na}^{+}$reabsorption in the TALH will always be equal to the difference between the product of the flow rate and the $\mathrm{Na}^{+}$concentration difference between plasma and the lumen at the static head (i.e., $\mathrm{Na}^{+}$reabsorption will be proportional to the flow rate).

We also found a small decrease in the protein abundance of NHE3 in claudin-2-KO kidney. Schnermann et al. reported that claudin-2-KO mice had an approximately $23 \%$ reduction in the single nephron GFR (SNGFR) that was attributed to tubuloglomerular feedback (35). It is conceivable that the reduced delivery of $\mathrm{Na}^{+}$to the PT might somehow signal to downregulate NHE3, a mechanism that might exist to maintain a glomerulotubular balance. However, our data (Table 1) and those of Muto et al. (34) showed no difference in the whole-kidney GFR between claudin-2-KO and WT mice. Alternatively the increased delivery of salt from the PT to the macula densa could suppress renin secretion from the juxtaglomerular apparatus, reduce angiotensin II levels, and thereby reduce NHE3 expression. Our analysis of the renin/angiotensin/aldosterone axis revealed that claudin-2-KO mice have a slight reduction in tissue renin expression in the kidney, but normal serum aldosterone levels (Supplemental Figure 4), so it is unclear whether reduced renin is the cause of the reduced NHE3 expression.

The shift in burden of $\mathrm{Na}^{+}$reabsorption from the PT to the TALH in claudin-2-KO mice occurs at the expense of increased oxygen consumption. Viewed thermodynamically, the free energy cost of transporting $\mathrm{Na}^{+}$uphill is dependent on the transtubular concentration gradient (specifically, it is proportional to the negative logarithm of the concentration gradient; ref. 46). Because of the large water permeability of the PT, there is almost no detectable transtubular concentration gradient for $\mathrm{Na}^{+}$in this nephron segment $(47,48)$, whereas the tubular fluid/plasma $\mathrm{Na}^{+}$concentration ratio approaches $0.2-0.4$ when measured by micropuncture at the end of the TALH (49). Thus, $\mathrm{Na}^{+}$reabsorption in the TALH necessarily requires more energy and hence greater $\mathrm{O}_{2}$ consumption than does the same amount of reabsorption occurring in the PT.

The consequence of the increased $\mathrm{O}_{2}$ consumption was that the outer medullas of claudin-2-KO mouse kidneys were more hypoxic than those of WT mice, even at baseline (Figure 4B). There was no change in hypoxia-inducible factor 1 (HIF-1), indicated by a lack of increased HIF-1 protein translocation to the nucleus, and no difference in RNA expression of HIF-1-targeted genes such as Vegf, Epo, Glut1, and Pgk between WT and KO mice (Supplemental Figure 15). There was also no change in ROS (Supplemental Figure 16). Nevertheless, this mild hypoxia reflects a serious deficit in the ability of the kidney to reduce $\mathrm{O}_{2}$ consumption to match $\mathrm{O}_{2}$ delivery. This is demonstrated by our finding that a modest reduction in $\mathrm{O}_{2}$ delivery, imposed by brief ( $23 \mathrm{~min}$ ) renal artery clamping, was sufficient to dramatically tip the delicate balance between $\mathrm{O}_{2}$ delivery and consumption and to greatly increase the susceptibility of the KO mice to ischemic tubule injury. When furosemide was given to claudin-2-KO mice, there was a 2.7-fold greater increase in $\mathrm{PO}_{2}$ in the outer medulla compared with that seen in WT mice. Furosemide pretreatment before IRI partially alleviated the injury, presumably by inhibiting NKCC2 and hence increasing $\mathrm{PO}_{2}$ in the outer medulla. It is conceivable that inherited or acquired variations in the PT paracellular transport pathway in humans might similarly affect the clinical susceptibility to acute ischemic kidney injury.

Although claudin-2-KO mice exhibit no salt wasting on either a normal or low-salt diet, Muto et al. had previously showed that these mice exhibited higher sodium excretion following a hypertonic saline infusion (34), and we have confirmed this in our KO mice. Our interpretation of this experiment, however, differs from that of Muto et al. The finding that saline-induced natriuresis is greater in claudin-2-KO mice than in WT mice demonstrates that it is not mediated by changes in paracellular $\mathrm{Na}^{+}$transport. Brenner et al. showed that saline-induced volume expansion reduced peritubular oncotic pressure, thus shifting the balance of Starling forces to inhibit PT fluid reabsorption $(50,51)$. To the extent that PT water reabsorption is primarily transcellular and mediated by aquaporins, we therefore predict that saline expansion should primarily inhibit transcellular transport in the PT, which should be similar in claudin-2-KO and WT mice.

How, then, to explain the observation that natriuresis is paradoxically increased in KO mice? Saline loading, by decreasing PT Na+ reabsorption, increases $\mathrm{Na}^{+}$delivery to the loop of Henle, where absolute and fractional $\mathrm{Na}^{+}$reabsorption is increased, a process likely mediated by increased flow. In addition, because in this experiment hypertonic saline is used, vasopressin release may also contribute by stimulating NKCC 2 activity. As we have shown, our claudin-2-KO mice were already compensating for decreased PT $\mathrm{Na}^{+}$reabsorption at baseline as a result of increased NKCC2 activity. We postulate that this NKCC2 activity is already maximally stimulated. Thus, KO mice are unable to further increase TALH Na ${ }^{+}$transport to mitigate an even greater $\mathrm{Na}^{+}$load delivered from the PT with hypertonic saline expansion. Hence, $\mathrm{KO}$ mice exhibit greater diuresis after saline infusion than do WT mice.

Several limitations of the present study deserve mention. Because the claudin-2 gene is on the $\mathrm{X}$ chromosome, we chose to confine our analysis to male WT and KO mice to simplify the breeding scheme. Also, our mice had constitutive $\mathrm{KO}$ of claudin-2. Since claudin-2 is expressed in other transporting epithelia and especially in the intestine, it is theoretically possible that an absence of claudin-2 in other tissues could explain our findings. This is very unlikely, though, because the key experiments, such as assays of oxygen consumption, are specifically confined to the kidney. Moreover, whereas claudin-2 is expressed throughout the intestinal epithelium including the villus in infant mice, it is confined to the crypts in adults (52). Consistent with this, in adult claudin-2-null mice, there was little change in the cation permeability of the intestine (25\% decrease in $\mathrm{P}_{\mathrm{Na}}$ compared with 
WT mice; ref. 52). We therefore believe that in adults, claudin-2 likely plays a minor role in intestinal $\mathrm{Na}^{+}$absorption. Our interpretation of the results here is also based on the assumption that the renal phenotype of KO mice is due to loss of PT claudin-2. However, we (29) and others $(30,53)$ have shown that claudin-2 is also highly expressed in the upper portion of the thin descending limb of long-looped nephrons. The role of this nephron segment is poorly understood, so the implications of claudin-2 deletion here are unknown.

The findings described here may provide insight into the evolutionary purpose of tight junctions. Transport of solutes and water by epithelia plays a critical role in the homeostasis of body fluid compartments in higher organisms and consumes a substantial amount of energy. Why epithelia evolved to have a leaky paracellular pathway is unknown. One possibility is that paracellular transport simply adds to the capacity of transcellular transport. However, this seems to add unnecessary complexity, since transcellular transport proteins are already so abundant and versatile. Here, we found that the defect in paracellular sodium reabsorption in the PT of the kidney in claudin-2-null mice can be completely compensated under even the most extreme circumstances that could be encountered in vivo (near-zero sodium diet), confirming that the contribution of paracellular transport is dispensable. The results we report here suggest a more nuanced reason for the existence of a paracellular transport pathway, namely that it evolved to enhance the efficiency of energy and oxygen utilization by the renal tubule epithelium. We show that the cost of losing paracellular transport is increased oxygen consumption, tissue hypoxia, and increased susceptibility to ischemic injury. This work provides insights into a fundamental metabolic process and may have broader significance for epithelial tissues.

\section{Methods}

Animals. Mice in which the single coding exon of claudin-2 on the $\mathrm{X}$ chromosome was replaced by a $\beta$ Geo/Puro cassette by homologous recombination (Supplemental Figure 1) and maintained on a B6;129F2 segregating background (B6;129S5-Cldn $\left.2^{\text {tmlLex/Mmcd }}\right)$ were purchased from Mutant Mouse Regional Resource Centers and backcrossed for 10 generations onto the C57BL/6J background. Muto et al. (34) and Schnermann et al. (35) also bred their claudin-2-KO mice onto the C57BL/6 strain, so our mice share the same genetic background with these published models. Supplemental Figure 2 shows the breeding strategy used to generate the hemizygous male claudin-2-null mice and WT male littermates that were used for these experiments.

Blood and urine studies. Mouse whole blood was collected through cardiac puncture, after which blood was left undisturbed at room temperature for 30 minutes to allow it to clot. The clot was then removed by centrifugation at $1,000 \times g$ for 10 minutes in a refrigerated centrifuge. Serum potassium and aldosterone were measured via a flame photometer (BWB Technologies) and an Aldosterone EIA Kit - Monoclonal (Cayman Chemical), respectively. To determine the urine $\mathrm{Na}^{+} /$ creatinine ratio, urine $\mathrm{Na}^{+}$concentration was measured with a sodium ion-sensitive microelectrode and urine creatinine with a colorimetric assay kit based on the Jaffe reaction (Cayman Chemical). BUN levels were measured in plasma samples using the QuantiChrom Urea Assay Kit ( BioAssay Systems) and plasma creatinine levels using an enzymatic method (Mouse Creatinine Assay Kit; Crystal Chem).
Low-sodium diet study. Mice were placed in metabolic cages for 9 days and fed custom purified rodent diets (Teklad; Harlan Laboratories). A control diet containing $0.3 \% \mathrm{Na}^{+}$(TD.120258) was provided for the first 5 days and then switched to a $\mathrm{Na}^{+}$-deficient diet containing $0.01 \% \mathrm{Na}^{+}$(TD.120259) for the next 4 days. Urine was collected daily, except on the first day after the switch to the $\mathrm{Na}^{+}$-deficient diet, when urine was collected every 8 hours. This was done to capture transient changes in the urine $\mathrm{Na}^{+}$excretion rate prior to attainment of a new steady state.

Hypertonic saline challenge. Mice were given $40 \mathrm{ml} / \mathrm{kg}$ BW of a $2 \%$ (wt/vol) sterile $\mathrm{NaCl}$ solution via i.p. injection. After the injection, the mice were housed in metabolic cages individually for 4 hours for urine collection. The urine $\mathrm{Na}^{+}$concentration was measured as before.

Diuretic challenge experiment. The protocol was modified from that described by Ecelbarger et al. $(54,55)$. As shown in Supplemental Figure 10, ten-week-old mice were acclimatized for 5 days in metabolic cages and then administered single i.p. injections of the following 3 diuretics and their matching vehicle according to the following schedule: $25 \mathrm{mg} / \mathrm{kg}$ BW furosemide (day 2); $1.4 \mathrm{mg} / \mathrm{kg}$ BW benzamil (day 9); and $25 \mathrm{mg} / \mathrm{kg}$ BW hydrochlorothiazide (day 16). Immediately after each injection of diuretic or vehicle, collection of urine was performed over a 4-hour period. Urine $\mathrm{Na}^{+}$concentration was measured as before.

RNA extraction and $q R T-P C R$. RNA was extracted from tissue homogenate with TRI Reagent (Sigma-Aldrich). First-strand cDNA was synthesized using iScript Reverse Transcription Supermix for RT-qPCR (Bio-Rad). qRT-PCR was performed using a CFX96 Touch Real-Time PCR Detection System and iTaq Universal SYBR Green Supermix (Bio-Rad) with the primers indicated in Supplemental Table 1. Expression levels were normalized to $\beta$-actin levels.

Urine MDA assay. Urinary malondialdehyde (MDA) was determined by measurement of thiobarbituric acid-reactive substances (TBARS). Aliquots of $500 \mu \mathrm{l}$ urine or MDA standards were mixed with $500 \mu$ thiobarbituric acid (1\%, pH 1.5) and boiled for 30 minutes. After cooling to room temperature, the absorbance was measured at 540-nm wavelength with a microplate reader. We also measured the absorbance of every urine sample and of thiobarbituric acid (TBA) as a blank. The final concentration of MDA was expressed as the difference between TBARS and blanks in order to diminish the interference of urine chromogens (56).

Homogenate preparation and quantitative immunoblotting. Homegenate preparation and quantitative immunoblotting were performed as described previously (57). Briefly, 1 whole kidney from each mouse was diced and suspended in $2 \mathrm{ml}$ isolation buffer (5\% sorbitol, 0.5 $\mathrm{mM}$ disodium EDTA, and $5 \mathrm{mM}$ histidine-imidazole buffer, $\mathrm{pH} 7.5$, with the addition of $167 \mathrm{mM}$ PMSF, $9 \mu \mathrm{g} / \mathrm{ml}$ aprotinin, and $5 \mu \mathrm{l} / \mathrm{ml}$ phosphatase inhibitor cocktail [Sigma-Aldrich]). Each sample was homogenized for 5 minutes at a low-speed setting with an Ultra-Tur$\operatorname{rax}$ T25 (IKA-Labortechnik) and then centrifuged at 2,000 $\times g$ for 10 minutes. Supernatants were retained, and the pellets were rehomogenized in another $2 \mathrm{ml}$ isolation buffer, recentrifuged, and pooled with the first supernatants. Nuclear and cytosol fractions of claudin-2 WT and KO kidney lysates were prepared with NE-PER Nuclear and Cytoplasmic Extraction Reagents (Thermo Fisher Scientific). Samples were denatured in SDS-PAGE sample buffer $\left(20\right.$ minutes, $\left.60^{\circ} \mathrm{C}\right)$, resolved by SDS-PAGE, transferred to PVDF membranes (Immobilon-FL; EMD Millipore), blocked with LI-COR blocking buffer, and then probed with the primary antibody. To verify uniform loading, 
loading gels were run (15 $\mu \mathrm{g}$ per lane) and stained with Coomassie blue. Random bands were quantified. The linearity of signal intensity was established by loading 0.5 volumes of each sample on each gel and verifying the halving of signal intensity. Equal loading of WT and KO kidney protein lysates represented the same percentage of whole kidney, since there was no difference in kidney weights (KW) between WT and KO mice (Supplemental Figure 17). The antibodies used in this study, dilutions, and vendors are listed in Supplemental Table 2. The immunoblot signals were quantitated with the Odyssey Infrared Imaging System (LI-COR). All comparisons were performed on samples run on the same membrane.

Immunofluorescence and immunohistochemical staining. In a separate group of WT and claudin-2-KO mice, kidneys were perfusion fixed via the heart with $4 \%$ paraformaldehyde in PBS. The fixed tissues were cryoprotected by overnight incubation with $30 \%$ sucrose in PBS, embedded in Tissue-Tek OCT Compound (Sakura Finetek), and frozen on dry ice. Cryosections (10- $\mu$ m thickness) from WT and KO animals were sliced and transferred to the same Superfrost Pluscharged glass slide (Fisher Scientific) for direct side-by-side processing and viewing. For immunofluorescence labeling, the sections were rehydrated, washed, and blocked with $1 \%$ BSA and $5 \%$ goat serum in PBS before antibody incubation. All antibodies used for immunostaining (listed in Supplemental Table 3) were diluted in 1\% BSA and 5\% goat serum in PBS. The sections were mounted in Prolong Antifade containing DAPI (Invitrogen) and air dried overnight. For immunohistochemical labeling, the sections were rehydrated and heated with a microwave oven in $0.01 \mathrm{~mol} / \mathrm{l}$ citrate buffer, $\mathrm{pH}$ 6.0, for 10 minutes and blocked with $10 \%$ goat serum in PBS at room temperature for 1 hour. The primary antibody was then added to the sections and incubated overnight at $4^{\circ} \mathrm{C}$ with $0.2 \%$ BSA in PBS. After application of the primary antibody, positive staining was detected using an HRP-conjugated secondary antibody with a DAB Substrate Kit (Vector Laboratories) for peroxidase staining. The sections were counterstained with Harris hematoxylin.

Renal oxygen consumption measurement. The ratio of net tubular $\mathrm{Na}^{+}$transport to $\mathrm{O}_{2}$ consumption $\left(\mathrm{T}_{\mathrm{Na}} / \mathrm{Q}_{\mathrm{O} 2}\right)$ in the kidney was determined using our previously described techniques (58-61). Adult mice ( 12 weeks of age) were anesthetized with isoflurane. The jugular vein, femoral artery, and renal vein were cannulated, and urine was collected by suprapubic catheter to monitor the flow rate $(\mathrm{V})$ and determine the $\mathrm{Na}^{+}$concentration $\left(\mathrm{U}_{\mathrm{Na}}\right)$. Warmed $1 \%$ albumin in $0.154 \mathrm{M} \mathrm{NaCl}(2 \% \mathrm{BW})$ was infused to replace surgical blood loss. To determine the GFR and RBF, ${ }^{14} \mathrm{C}$-inulin and ${ }^{3} \mathrm{H}-\mathrm{PAH}$ were infused. After a 30-minute equilibration, urine was collected over two 30-minute periods, and blood was sampled at the midpoint of each period for liquid scintillation counting and clearances were calculated. At the end of the study, blood was drawn from the femoral artery and renal vein for measurement of $\mathrm{O}_{2}\left(\mathrm{~A}_{\mathrm{O} 2}\right.$ and $\mathrm{V}_{\mathrm{O} 2}$, respectively) in a blood gas analyzer (i-STAT1; Abbott Laboratories) and used to calculate total $\mathrm{O}_{2}$ content. $\mathrm{T}_{\mathrm{Na}}$ is the total kidney transport of $\mathrm{Na}^{+}$and is equal to filtered $\mathrm{Na}^{+}$minus excreted $\mathrm{Na}^{+}: \mathrm{T}_{\mathrm{Na}}=$ $\left(\right.$ GFR X P $\left.\mathrm{P}_{\mathrm{Na}}\right)-\mathrm{U}_{\mathrm{Na}} \mathrm{V}$. Renal oxygen consumption $\left(\mathrm{Q}_{\mathrm{O} 2}\right)$ was calculated by the renal extraction of $\mathrm{O}_{2}$ factored by $\mathrm{RBF}$, where the renal extraction of $\mathrm{O}_{2}$ was calculated by the arterial-venous difference. Thus, $\mathrm{Q}_{\mathrm{O} 2}=\mathrm{RBF} X\left(\mathrm{~A}_{\mathrm{O} 2}-\mathrm{V}_{\mathrm{O} 2}\right)$. The efficiency of $\mathrm{O}_{2}$ utilization for the transport of $\mathrm{Na}^{+}$(not corrected for the basal metabolic rate) was calculated by the ratio of $\mathrm{T}_{\mathrm{Na}} / \mathrm{Q}_{\mathrm{O} 2}$.
Measurement of intrarenal oxygen tension. The intrarenal partial pressure of $\mathrm{O}_{2}\left(\mathrm{P}_{\mathrm{O} 2}\right)$ was measured with a Clark-type $\mathrm{O}_{2}$ microelectrode (OX-10; Unisense) with a tip diameter of 8 to $12 \mu \mathrm{m}$, connected to an ultra-high impedance picoammeter (Unisense). Electrodes were inserted into the immobilized kidney of anesthetized mice and advanced to the outer or inner cortex $(0.5-1.0 \mu \mathrm{m})$ or to the outer medulla $(1.5 \mu \mathrm{m})$. The electrodes were stabilized, and $\mathrm{P}_{\mathrm{O} 2}$ was recorded for 2 to 4 minutes.

Bilateral renal IRI model. Eight- to ten-week-old mice were anesthetized with xylazine $(10 \mathrm{mg} / \mathrm{kg}$ i.p.) and ketamine (90-120 mg/ kg i.p.). The kidneys were exposed through flank incisions, and both renal pedicles were occluded with microaneurysm clamps (Fine Science Tools). The body temperature was maintained between $36.3^{\circ} \mathrm{C}$ and $36.5^{\circ} \mathrm{C}$ using a rectal temperature probe and thermostatically controlled homeothermic blanket system (Harvard Apparatus) set to $36.5^{\circ} \mathrm{C}$. After exactly 23 minutes, the clamps were removed, reperfusion of the kidneys was confirmed visually, and the mice were sutured closed. The mice were given $0.5 \mathrm{ml}$ warm, sterile $0.9 \%$ saline s.c. at the end of the operation and before they recovered from anesthesia. Blood was collected immediately before and 24 and 48 hours after the surgery by tail nicking. One kidney from each mouse was harvested for RNA isolation and qRT-PCR for Kim1. The other kidney was fixed with $4 \%$ buffered paraformaldehyde, and paraffinembedded sections were stained with Periodic acid-Schiff (PAS) for histological scoring. Separate groups of WT and KO mice underwent furosemide pretreatment before ischemia-reperfusion surgery. In these groups, the mice were administered single i.p. injections of $25 \mathrm{mg} / \mathrm{kg}$ BW furosemide in $0.5 \mathrm{ml}$ total volume of saline 2 hours prior to the start of surgery. Furosemide-treated mice were given 1 $\mathrm{ml}$ saline s.c. at the end of surgery.

The method for quantifying acute kidney injury was adapted from that previously reported (62). Briefly, kidney images were acquired (Spot, v5.0; Diagnostic Instruments) from mid-sagittal sections of whole kidneys stained by the PAS method. The total kidney area and areas of tubular necrosis were measured using Image J 64-bit software (NIH) (63). The acute injury index was calculated by dividing the injured area by the total area.

Statistics. Statistical analyses were performed with SPSS Statistics software, version 22 (IBM). Data are expressed as the mean \pm SEM. A 2-tailed Student's $t$ test was used to test differences between means in 2-group comparisons. ANOVA was used to test for differences in multigroup experiments. Mixed-factor ANOVA was used to test the between-subjects effect of genotype (WT vs. KO) and the within-subjects effect of diuretics (furosemide vs. vehicle) on the outer medullary $\mathrm{pO}_{2}$. Because a significant (genotype $\mathrm{x}$ diuretic) interaction was detected, simple-effects analysis was then performed to determine the effect of furosemide within each genotype and the effect of genotype within vehicle- and furosemide-treated conditions, and the $P$ value was multiplied by the number of tests performed within each factor to protect against a family-wise type I error due to multiple comparisons (an application of Bonferroni's procedure). Similarly, mixed ANOVA followed by simple-effects analysis was used to test the effect of genotype on BUN at 0, 24, and 48 hours, as well as serum creatinine, KIM-1 levels, and kidney injury score at 48 hours after bilateral renal IRI, and the effect of furosemide pretreatment versus control within the WT and KO mouse groups at each time point. $P$ values of less than 0.05 were considered significant. 
Study approval. All animal experiments were performed in accordance with NIH guidelines on the use of laboratory animals and were approved by the IACUCs of the University of Kansas Medical Center, Georgetown University Medical Center, and the University of Southern California.

\section{Author contributions}

LP, ASLY, WJW, and AAM designed the studies. LP, GS, MTXN, NK, LM, MZ, JL, JC, TAF, and WJW conducted the experiments. LP, ASLY, TAF, WJW, and AAM analyzed the data. LP, ASLY, WJW, and AAM wrote the manuscript.

\section{Acknowledgments}

This work is supported by NIH NIDDK grants R01DK062283 (to A.S.L. Yu) and R01DK083785 (to A.A. McDonough) and NHLBI grant HL089583 (to W.J. Welch). The Confocal Imaging Core at the University of Kansas Medical Center is supported by NIH grant P20GM104936.

Address correspondence to: Alan S.L. Yu, The Kidney Institute, University of Kansas Medical Center, 3901 Rainbow Blvd, Mail Stop 3018, Kansas City, Kansas 66160, USA. Phone: 913. 588.9252; E-mail: ayu@kumc.edu.
1. Farquhar MG, Palade GE. Junctional complexes in various epithelia. JCell Biol. 1963;17:375-412.

2. Staehelin LA. Further observations on the fine structure of freeze-cleaved tight junctions. J Cell Sci.1973;13(3):763-786.

3. Whittembury G, Rawlins FA. Evidence of a paracellular pathway for ion flow in the kidney proximal tubule. Electromicroscopic demonstration of lanthanum precipitate in the tight junction. Pflugers Arch. 1971;330(4):302-309.

4. Machen TE, Erlij D, Wooding FB. Permeable junctional complexes. The movement of lanthanum across rabbit gallbladder and intestine. JCell Biol. 1972;54(2):302-312.

5. Martínez-Palomo A, Erlij D. The distribution of lanthanum in tight junctions of the kidney tubule. Pflugers Arch. 1973;343(3):267-272.

6. Frömter E, Diamond J. Route of passive ion permeation in epithelia. Nature New Biol. 1972;235(53):9-13.

7. Tisher CC, Yarger WE. Lanthanum permeability of the tight junction (zonula occludens) in the renal tubule of the rat. Kidney Int. 1973;3(4):238-250.

8. Fagerberg L, Jonasson K, von Heijne G, Uhlén M, Berglund L. Prediction of the human membrane proteome. Proteomics. 2010;10(6):1141-1149.

9. Uhlen M, et al. Towards a knowledgebased Human Protein Atlas. Nat Biotechnol. 2010;28(12):1248-1250.

10. McDonough AA, Thomson SC. Metabolic basis of solute transport. In: Taal MW, Chertow GM, Marsden PA, Skorecki K, Yu AS, Brenner BM, eds. Brenner and Rector's The Kidney. 9th ed. Philadelphia, Pennsylvania, USA: Elsevier; 2012:138-157.

11. Lübbers DW, Baumgärtl H. Heterogeneities and profiles of oxygen pressure in brain and kidney as examples of the $\mathrm{pO} 2$ distribution in the living tissue. Kidney Int. 1997;51(2):372-380.

12. Brodwall EK, Laake H. The relation between oxygen consumption and transport of sodium in the human kidney. Scand J Clin Lab Invest. 1964;16:281-286.

13. Soltoff SP. ATP and the regulation of renal cell function. Annu Rev Physiol. 1986;48:9-31.

14. Kiil F, Aukland K, Refsum HE. Renal sodium transport and oxygen consumption. Am JPhysiol. 1961;201:511-516.

15. Thurau K. Renal Na-reabsorption and O2-uptake in dogs during hypoxia and hydrochlorothiazide infusion. Proc Soc Exp Biol Med. 1961;106:714-717.

16. Knox FG, Fleming JS, Rennie DW. Effects of osmotic diuresis on sodium reabsorption and oxygen consumption of kidney. Am J Physiol. 1966;210(4):751-759.

17. Torelli G, Milla E, Faelli A, Costantini S. Energy requirement for sodium reabsorption in the in vivo rabbit kidney. Am J Physiol. 1966;211(3):576-580.

18. Neumann KH, Rector FC. Mechanism of $\mathrm{NaCl}$ and water reabsorption in the proximal convoluted tubule of rat kidney. J Clin Invest. 1976;58(5):1110-1118.

19. Berry CA, Warnock DG, Rector FC Jr. Ion selectivity and proximal salt reabsorption. $A m \mathrm{~J}$ Physiol. 1978;235(3):F234-F245.

20. Schafer JA, Patlak CS, Andreoli TE. A component of fluid absorption linked to passive ion flows in the superficial pars recta.J Gen Physiol. 1975;66(4):445-471.

21. Warnock DG, Burg MB. Urinary acidification: $\mathrm{CO} 2$ transport by the rabbit proximal straight tubule. Am J Physiol. 1977;232(1):F20-F25.

22. Barratt LJ, Rector FC Jr, Kokko JP, Seldin DW. Factors governing the transepithelial potential difference across the proximal tubule of the rat kidney. J Clin Invest. 1974;53(2):454-464.

23. Moe OW, Berry CA, Rector FC Jr. Renal transport of glucose, amino acids, sodium, chloride and water. In: Brenner BM, ed. Brenner and Rector's The Kidney. 6th ed. Philadelphia, Pennsylvania, USA: Saunders; 2000:375-416.

24. Angelow S, Ahlstrom R, Yu AS. Biology of claudins. Am J Physiol Renal Physiol. 2008;295(4):F867-F876.

25. Günzel D, Yu AS. Claudins and the modulation of tight junction permeability. Physiol Rev. 2013;93(2):525-569.

26. Hou J, Rajagopal M, Yu AS. Claudins and the kidney. Annu Rev Physiol. 2013;75:479-501.

27. Mineta K, et al. Predicted expansion of the claudin multigene family. FEBS Lett. 2011;585(4):606-612.

28. Suzuki H, et al. Crystal structure of a claudin provides insight into the architecture of tight junctions. Science. 2014;344(6181):304-307.

29. Enck AH, Berger UV, Yu AS. Claudin-2 is selectively expressed in proximal nephron in mouse kidney. Am JPhysiol Renal Physiol. 2001;281(5):F966-F974.

30. Kiuchi-Saishin Y, Gotoh S, Furuse M, Takasuga A, Tano Y, Tsukita S. Differential expression patterns of claudins, tight junction membrane proteins, in mouse nephron segments. J Am Soc Nephrol. 2002;13(4):875-886.

31. Furuse M, Furuse K, Sasaki H, Tsukita S. Con- version of zonulae occludentes from tight to leaky strand type by introducing claudin-2 into Madin-Darby canine kidney I cells. J Cell Biol. 2001;153(2):263-272

32. Amasheh S, et al. Claudin-2 expression induces cation-selective channels in tight junctions of epithelial cells. J Cell Sci. 2002;115(pt 24):4969-4976.

33. Yu AS, et al. Molecular basis for cation selectivity in claudin-2-based paracellular pores: identification of an electrostatic interaction site. J Gen Physiol. 2009;133(1):111-127.

34. Muto S, et al. Claudin-2-deficient mice are defective in the leaky and cation-selective paracellular permeability properties of renal proximal tubules. Proc Natl Acad Sci USA. 2010;107(17):8011-8016.

35. Schnermann J, Huang Y, Mizel D. Fluid reabsorption in proximal convoluted tubules of mice with gene deletions of claudin-2 and/ or aquaporin1. Am J Physiol Renal Physiol. 2013;305(9):F1352-F1364.

36. Waanders F, van Timmeren MM, Stegeman CA, Bakker SJ, van Goor H. Kidney injury molecule-1 in renal disease. J Pathol. 2010;220(1):7-16.

37. van Timmeren MM, van den Heuvel MC, Bailly V, Bakker SJ, van Goor H, Stegeman CA. Tubular kidney injury molecule-1 (KIM-1) in human renal disease. J Pathol. 2007;212(2):209-217.

38. Landwehr DM, Klose RM, Giebisch G. Renal tubular sodium and water reabsorption in the isotonic sodium chloride-loaded rat. Am J Physiol. 1967;212(6):1327-1333.

39. Morgan T, Berliner RW. A study by continuous microperfusion of water and electrolyte movements in the loop of Henle and distal tubule of the rat. Nephron. 1969;6(3):388-405.

40. Abe M, O'Connor P, Kaldunski M, Liang M, Roman RJ, Cowley AW. Effect of sodium delivery on superoxide and nitric oxide in the medullary thick ascending limb. Am J Physiol Renal Physiol. 2006;291(2):F350-F357.

41. Hong NJ, Garvin JL. NADPH oxidase 4 mediates flow-induced superoxide production in thick ascending limbs. Am J Physiol Renal Physiol. 2012;303(8):F1151-F1156.

42. Juncos R, Garvin JL. Superoxide enhances $\mathrm{Na}-\mathrm{K}-2 \mathrm{Cl}$ cotransporter activity in the thick ascending limb. Am J Physiol Renal Physiol. 2005;288(5):F982-F987.

43. Ortiz PA, Garvin JL. Superoxide stimulates $\mathrm{NaCl}$ absorption by the thick ascending limb. Am J Physiol Renal Physiol. 2002;283(5):F957-F962.

44. Cabral PD, Garvin JL. Luminal flow regulates NO 


\section{RESEARCH ARTICLE}

and O2(-) along the nephron. Am J Physiol Renal Physiol. 2011;300(5):F1047-F1053.

45. Burg MB. Thick ascending limb of Henle's loop. Kidney Int. 1982;22(5):454-464.

46. Stephenson JL, Tewarson RP, Mejia R. Quantitative analysis of mass and energy balance in nonideal models of the renal counterflow system. Proc Natl Acad Sci U S A. 1974;71(5):1618-1622.

47. Windhager EE, Giebisch G. Micropuncture study of renal tubular transfer of sodium chloride in the rat. Am J Physiol. 1961;200:581-590.

48. Ullrich KJ, et al. Micropuncture study of composition of proximal and distal tubular fluid in rat kidney. Am J Physiol. 1963;204:527-531.

49. Burg M, Good D. Sodium chloride coupled transport in mammalian nephrons. Annu Rev Physiol. 1983;45:533-547.

50. Brenner BM, Troy JL, Daugharty TM. On the mechanism of inhibition in fluid reabsorption by the renal proximal tubule of the volume-expanded rat. J Clin Invest. 1971;50(8):1596-1602.

51. Ichikawa I, Brenner BM. Mechanism of inhibition of proximal tubule fluid reabsorption after exposure of the rat kidney to the physical effects of expansion of extracellular fluid volume. J Clin Invest. 1979;64(5):1466-1474.
52. Tamura A, et al. Loss of claudin-15, but not claudin-2, causes $\mathrm{Na}^{+}$deficiency and glucose malabsorption in mouse small intestine. Gastroenterology. 2011;140(3):913-923.

53. Lee JW, Chou CL, Knepper MA. Deep sequencing in microdissected renal tubules identifies nephron segment-specific transcriptomes. JAm Soc Nephrol. 2015;26(11):2669-2677.

54. Madala Halagappa VK, Tiwari S, Riazi S, Hu $\mathrm{X}$, Ecelbarger CM. Chronic candesartan alters expression and activity of NKCC2, NCC, and $\mathrm{ENaC}$ in the obese Zucker rat. Am J Physiol Renal Physiol. 2008;294(5):F1222-F1231.

55. Tiwari S, Li L, Riazi S, Halagappa VK, Ecelbarger CM. Sex and age result in differential regulation of the renal thiazide-sensitive $\mathrm{NaCl}$ cotransporter and the epithelial sodium channel in angiotensin II-infused mice. Am J Nephrol. 2009;30(6):554-562.

56. Zhou H, et al. Urinary marker for oxidative stress in kidneys in cisplatin-induced acute renal failure in rats. Nephrol Dial Transplant. 2006;21(3):616-623.

57. Nguyen MT, et al. Effects of $\mathrm{K}^{+}$-deficient diets with and without $\mathrm{NaCl}$ supplementation on $\mathrm{Na}^{+}, \mathrm{K}^{+}$, and $\mathrm{H} 2 \mathrm{O}$ transporters' abundance along the nephron. Am J Physiol Renal Physiol. 2012;303(1):F92-104.

58. Welch WJ, Baumgärtl H, Lübbers D, Wilcox CS. Renal oxygenation defects in the spontaneously hypertensive rat: role of AT1 receptors. Kidney Int. 2003;63(1):202-208.

59. Welch WJ, Mendonca M, Aslam S, Wilcox CS. Roles of oxidative stress and AT1 receptors in renal hemodynamics and oxygenation in the postclipped 2K,1C kidney. Hypertension. 2003;41(3 pt 2):692-696.

60. Welch WJ, Blau J, Xie H, Chabrashvili T, Wilcox CS. Angiotensin-induced defects in renal oxygenation: role of oxidative stress. Am J Physiol Heart Circ Physiol. 2005;288(1):H22-H28.

61. Lai EY, et al. Effects of the antioxidant drug tempol on renal oxygenation in mice with reduced renal mass. Am J Physiol Renal Physiol. 2012;303(1):F64-F74.

62. Zhang S, et al. Dietary phosphate restriction suppresses phosphaturia but does not prevent FGF23 elevation in a mouse model of chronic kidney disease. Kidney Int. 2013;84(4):713-721.

63. Schneider CA, Rasband WS, Eliceiri KW. NIH Image to ImageJ: 25 years of image analysis. Nat Methods. 2012;9(7):671-675. 